\title{
A Mini Review on Testing Methods for Mechanical Properties of Natural Fibre Honeycomb Sandwich Structure and Fractography Analysis
}

\author{
Nahiyan Al-Azad, Nur Hafidah Binti Dedifitrianto, Mohd. Kamal Mohd. Shah* \\ Advanced Composite Research Group, Faculty of Engineering, Universiti Malaysia Sabah, Sabah, Malaysia \\ Email: ^makamalms@ums.edu.my
}

How to cite this paper: Al-Azad, N., Dedifitrianto, N.B. and Shah, M.K.M. (2021) A Mini Review on Testing Methods for Mechanical Properties of Natural Fibre Honeycomb Sandwich Structure and Fractography Analysis. Journal of Materials Science and Chemical Engineering, 9, 29-38.

https://doi.org/10.4236/msce.2021.95003

Received: April 21, 2021

Accepted: May 24, 2021

Published: May 27, 2021

Copyright $\odot 2021$ by author(s) and Scientific Research Publishing Inc. This work is licensed under the Creative Commons Attribution International License (CC BY 4.0).

http://creativecommons.org/licenses/by/4.0/

\begin{abstract}
This paper is a review of the past research of mechanical testing methods for natural fibre honeycomb sandwich structure as well as failure modes analysis at a microscopic level by using Scanning Electron Microscope (SEM). As the world is garnering attention towards renewable resources for environmental purposes, studies of natural fibre have been increasing as well as the application of natural fibre throughout various industries such as aerospace, automobiles, and construction sectors. This paper is started with brief information regarding the honeycomb sandwich structure, introduction to natural fibre, its applications as well as the factors affecting the performances of the structure. Next, the mechanical testing methods are listed out as well as the expected outcomes obtained from the respective testing. The mechanical properties are also identified by conducting lab tests according to the ASTM standard for sandwich and core structures. The microstructure of the deformed samples is then examined under Scanning Electron Microscope (SEM) by using different magnifications to study the failure mechanisms of the samples. The images obtained from the SEM test are analyzed by using fractography which will show the failure modes of the samples. This article is based on past research conducted by professional on the related topic.
\end{abstract}

\section{Keywords}

Natural Fibre Honeycomb Sandwich Structure, Testing Methods, ASTM Standard, SEM Test

\section{Introduction}

A sandwich structure composite consists of a thin, dense, and strong face sheet 
layered with a lightweight core. It is broadly applied in industries requires lightweight design such as automotive and aerospace sectors [1]. The performance of a sandwich structure highly depends on the types of material used for the core and the geometric parameters. Some common materials reported that are typically utilized for the construction of the core are aluminium [2] [3], Nomex [4], Kraft paper [5], and carbon fibre [6]. The technology behind sandwich structure offers various benefits including, lightweight, higher strength and high energy absorption.

Honeycomb structure is recently being considered as the core as it offers good mechanical and crushing as well as acoustic properties, fluid control, low dielectric properties, low thermal conductivity coefficients, small cross-sectional area, and a large exposed area within the cells [7] [8]. Typically, honeycomb core is made up of metallic or composite material. The study has been made for aluminium honeycomb sandwich structure to prove that the honeycomb cell size is the most important parameter for the core under bending and in-panel compress tests [8]. The mechanical properties of the core can be improved by reinforcing the materials with other composites such as ceramics or glass fibres.

Natural fibres are fibres that can be easily gained and extracted from plants, vegetables, and animals' sources. Natural fibres are advantageous and sustainable than synthetic fibres which led the industrial sectors to utilize natural fibres in various field such as automotive, aerospace and construction [1]. Natural fibre honeycomb sandwich structure is a construction of sandwich panel with a honeycomb core that is made up of natural fibre, as it is called. Hence, this structure has attracted more attention for its benefits especially in the construction industry as well as its ability to sustain the environment. There are many studies that have been conducted involving various natural fibres which resulted in different properties for respective natural fibres [4] [5] [6] [7] [8]. From these studies, the moisture conditions and humidity as well as the testing methods, are varied. However, the performances of natural fibres are depending on many factors including the chemical composition, physical properties, mechanical properties, microfibrillar angle, defects, structure and the interaction between the fibre and the polymer as well as the crystalline cell dimensions [6] [7] [8].

Other than that, the behaviours of natural fibre also depend on the weight percent of the fibre, its orientation, length, texture, and its hydrophilic nature. Nonetheless, hydrophilic fibre and hydrophobic matrix have poor congruent which will give an impact on the structure, yet it can be improved by using compatibilizers to develop better adhesion between the fibre and the matrix [9] [10].

Natural fibre honeycomb sandwich structure offers various advantages in industries due to the mechanical properties and high-performance. Nevertheless, the number of researches on factography analysis that have been done on natural fibre honeycomb sandwich structure is low. Hence, as this paper will provide a review on the testing methods and standards to study the mechanical behaviours of natural fibre honeycomb sandwich structure, as well as fractography analysis to identify the failure mechanism, this paper will be very beneficial as it 
can be referred for future studies of natural fibre honeycomb sandwich structure to broaden the implementation of this structure especially in construction industry.

\section{Research Method in SEM}

\subsection{Testing Methods}

As the performance and properties of the face sheets, core and the adhesive varies depending on the materials, design parameters and the manufacturing process, an adequate testing is required to prevent failures. Therefore, in order to select the most suitable materials, a correct development process, help in design process as well as ensuring the quality control, standardized or specific tests are vital for these purposes.

The testing for natural fiber-based sandwich composites is vital to assess the quality of the materials used for manufacturing purposes. It will help in evaluating and optimizing the usage of materials in the structures. To study the effects of equipment and tool design, the sandwich panels also need to be tested according to the suitable testing methods. From the test, the quality of product can be determined. Hence, it will bring huge opportunities to manufacturer to overcome any problems faced in the structure whether the materials are unsuitable or other mechanical defects of the structure that impacted the performances such as crack and fractures.

In attempt to study the mechanical properties and the structural integrity of the face sheets and the honeycomb core, there are various test methods that can be used according to ASTM Standards Test Methods and the Military Standard 401B, Sandwich Constructions and Core Materials: General Test Methods. Table 1 below from source [11] lists out the tests that have been used in previous research studies on honeycomb panels and core according to the names and types of the test as well as the findings expected from the respective test.

Table 1. Tests for sandwiched composite panels. Source Ref [11].

\begin{tabular}{|c|c|c|}
\hline Name of the Test & Type of Test & Outcome/Observation \\
\hline Wear and Tear & & $\begin{array}{l}\text { Investigate performance properties for long-term usage of } \\
\text { the material. }\end{array}$ \\
\hline \multirow{2}{*}{$\begin{array}{l}\text { Tensile Strength \& } \\
\text { Modulus Test }\end{array}$} & Shear & $>$ Max. load required to shear. \\
\hline & $\begin{array}{c}\text { Flatwise Tensile } \\
\text { Test }\end{array}$ & $>$ Measure the adhesive bond strength. \\
\hline Strength Test & $\begin{array}{c}\text { Flexural } \\
\text { Strength Test \& } \\
\text { Modulus Test }\end{array}$ & $\begin{array}{l}\text { Determine the flexibility of the specimen under load to } \\
\text { prevent deformation. } \\
\text { Measure the stress experienced by the materials at the } \\
\text { failure moment. }\end{array}$ \\
\hline $\begin{array}{l}\text { Material } \\
\text { Construction Tests }\end{array}$ & & $\begin{array}{l}\text { Analyze construction issues (adhesive bond strength, } \\
\text { resistance to deformation under load, exposure to moisture). }\end{array}$ \\
\hline Edge Bearing Test & & $\begin{array}{l}\text { Determine the bearing strength of fasteners in a laminate } \\
\text { under tension loading. }\end{array}$ \\
\hline $\begin{array}{c}\text { Impact (Puncture) } \\
\text { Test }\end{array}$ & & $\begin{array}{l}\text { Measure the ability of materials to resist puncture, withstand } \\
\text { shock loading and fractures during shock loading. }\end{array}$ \\
\hline
\end{tabular}




\subsection{ASTM Standard for Sample Testing}

Before the test is conducted, the samples involved need to be made sure to be properly conditioned as the temperature and humidity of the surrounding will affect the sample. Thus, ASTM D618-61 provides the outline for specimen conditioning requirements before actual testing as shown in Table 2 below.

The honeycomb core is another important component of a lightweight sandwich structure. The different geometric parameters of the honeycomb core have a great influence on the mechanical properties of the sandwich structure. Thus, to further investigate the bending response brought from honeycomb core, sample testing should be done according to the most suited testing standard. The ASTM standard that has been used for the past research is shown in Table 3 for sandwich panel and honeycomb core respectively.

\section{Results and Analysis of SEM Image}

Scanning Electron Microscope (SEM) is a tool that has the function to magnify small features or objects that cannot be observed by human sight. Different from typical microscope which using optical light to observe, SEM use electron beam with high energy on the sample surface to form images. In the previous study, the mechanical properties of samples are tested by some physical testing. After

Table 2. Sample conditioning requirement for sandwich panel. Source Ref [11].

\begin{tabular}{ccc}
\hline No. & Parameter & Requirement \\
\hline 1. & Relative Humidity & $23^{\circ} \mathrm{C} \pm 2{ }^{\circ} \mathrm{C}$ \\
\hline 2. & Temperature & $50 \pm 5 \%$ \\
\hline 3. & Duration (min) relative to test specimen dimension & $\begin{array}{l}40 \mathrm{hrs} \text { for specimen } \leq 6.33 \mathrm{~mm} \text { thick } \\
88 \mathrm{hrs} \text { for specimen } \geq 6.35 \mathrm{~mm} \text { thick }\end{array}$ \\
\hline
\end{tabular}

Table 3. Specifications applicable for cores and sandwich panels. Source Ref [11].

\begin{tabular}{|c|c|c|}
\hline No. & ASTM Specification & Findings \\
\hline \multicolumn{3}{|c|}{ Cores } \\
\hline 1. & $\mathrm{C} 273 / \mathrm{C} 273 \mathrm{M}$ & Core Shear Properties \\
\hline 2. & C365/C365M & Core Flatwise Compressive Properties \\
\hline 3. & C393/C393M & Core Shear Properties by Beam Flexure \\
\hline 4. & C394 & Core Shear Fatigue \\
\hline 5. & $\mathrm{D} 7336 / \mathrm{D} 7336 \mathrm{M}$ & Core Static Energy Absorption \\
\hline \multicolumn{3}{|c|}{ Sandwich Panels } \\
\hline 1. & C297/C297M & Sandwich Flatwise Tensile Strength \\
\hline 2. & C364/C364M & Sandwich Edgewise Compressive Strength \\
\hline 3. & C480 & Sandwich Flexural Creep \\
\hline 4. & D6416/D6416M & Sandwich 2D Plate Flexural Properties \\
\hline 5. & D7249/D7249M & Sandwich Facing Properties by Beam Flexure \\
\hline 6. & D7250/D7250M & Sandwich Beam Flexural and Shear Stiffness \\
\hline
\end{tabular}


that, the deformed samples will be examined under Scanning electron Microscope (SEM) by using several magnifications to study the microstructure defects of the sample. The failure analysis of the sample obtained from the images of SEM will be analyzed by using fractography.

Typically, the honeycomb sandwich structure constructed from various types of materials is tested according to the standard. When the sample is observed under SEM, there are many failure modes that can be found on the sample surface and core. From the previous studies, the images obtained from the SEM micrographs were analysed by using fractography which shown failure mechanisms of the structure such as matrix breakage [11], fracture, fibre pull out, indentation [11], axial splitting [12], cracks and porosity [13]. From the analysis made on the sample, further enhancement of composite properties can be developed to get better mechanical properties and exhibit better performance of the composite structure involved. The example of micrographs under Scanning Electron Microscope can be seen in Figure 1.

More failure modes can be studied from SEM and fractography analysis can be seen from the research that has been done by Cecilia Daimin et al. on the micro failure of eco board. The magnifications of SEM that has been used are different to identify the failure modes of the samples ranging in between 20X to 85X of magnifications. The SEM images of the specimens are shown in the Table 4 below through fractography.
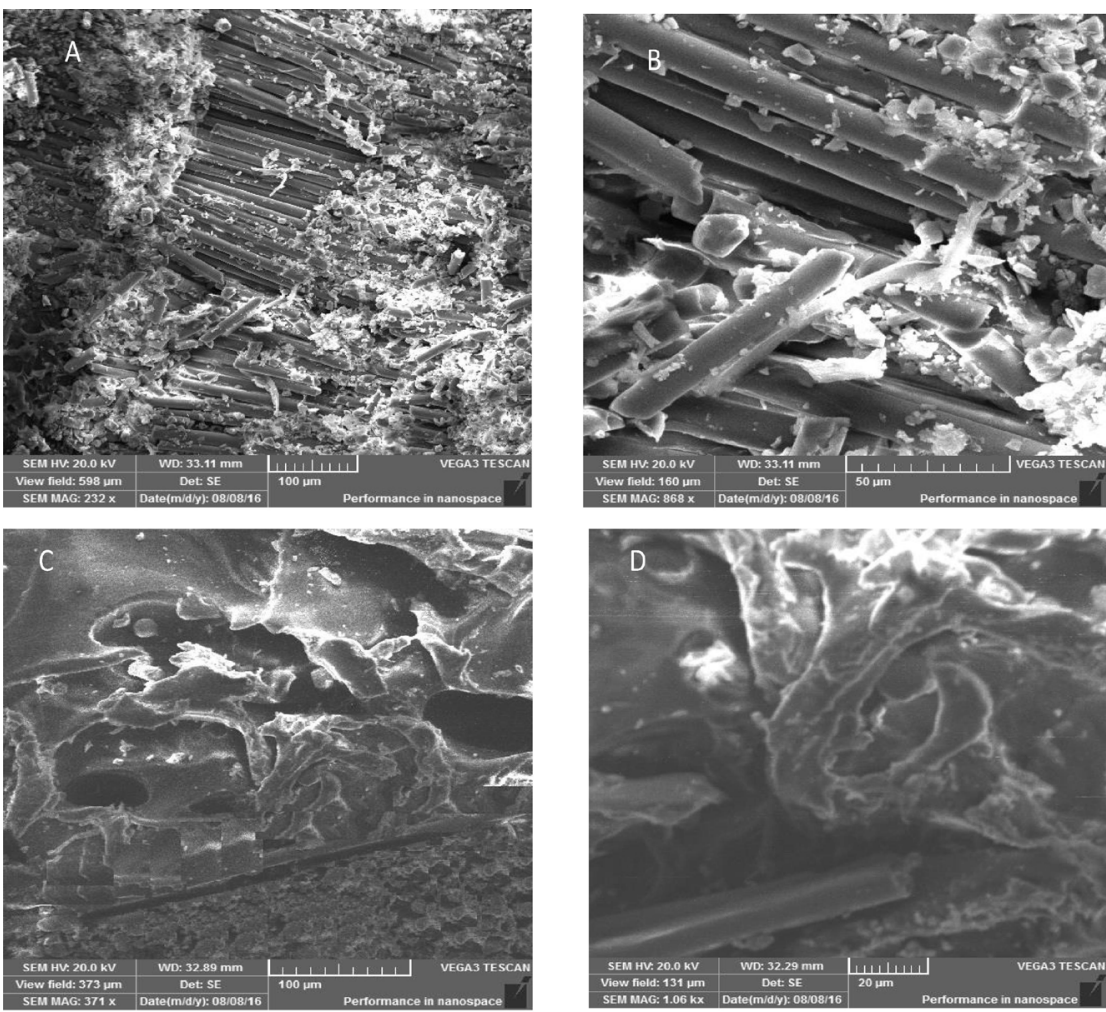

Figure 1. Scanning electron microscope images for (A) Compression failure of facing (B) Failure of fiber glass facing (C) Core and facing interface delamination (D) Interfacial shear failure. Source Ref [11] [12] [13]. 
Table 4. SEM images of the coated and uncoated specimens. Source Ref [14].






\section{Continued}

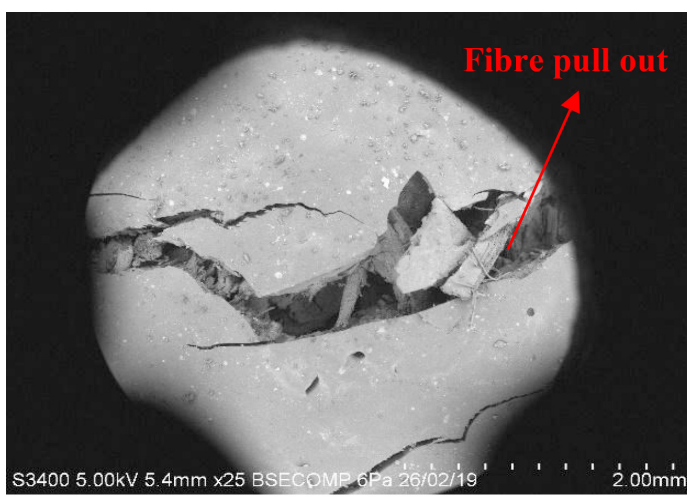

25X magnification

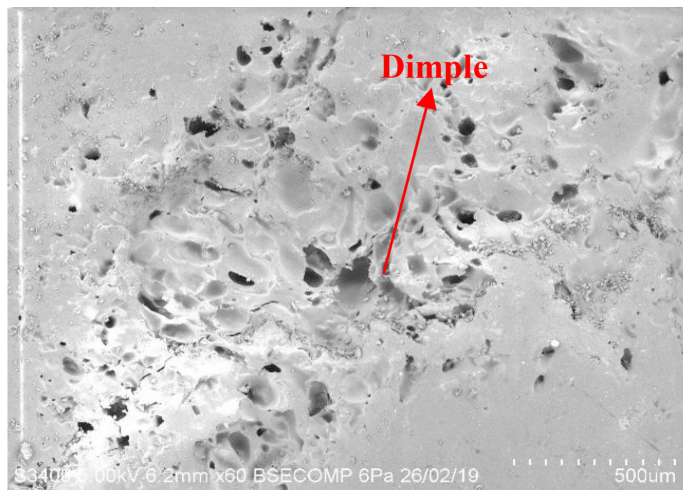

$60 \mathrm{X}$ magnification

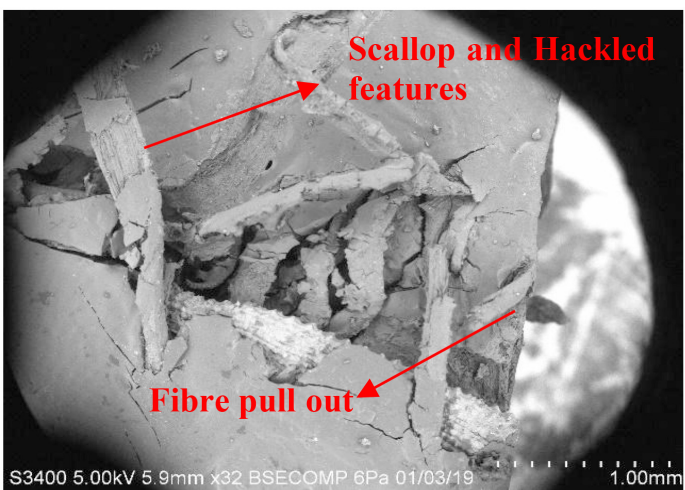

32X magnification

OPEFB: RH

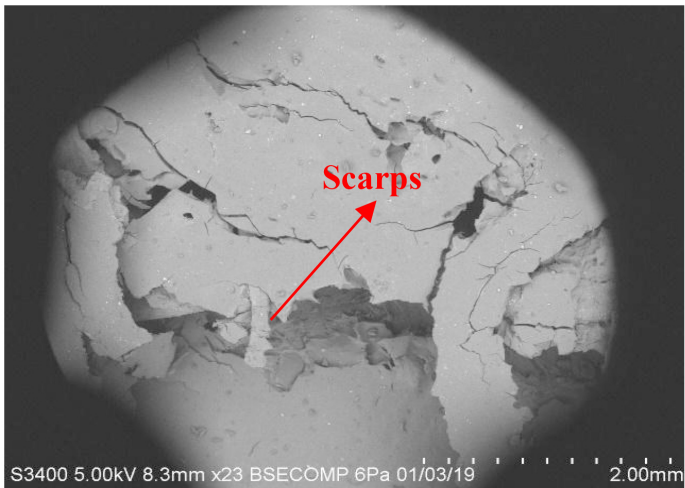

23X magnification

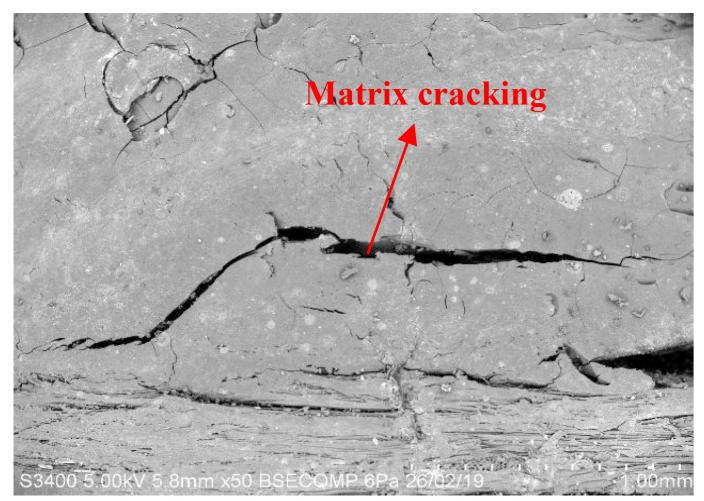

50X magnification

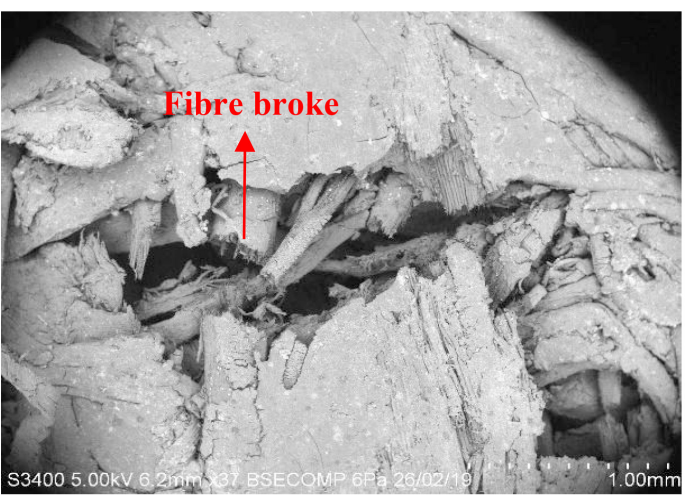

37X magnification

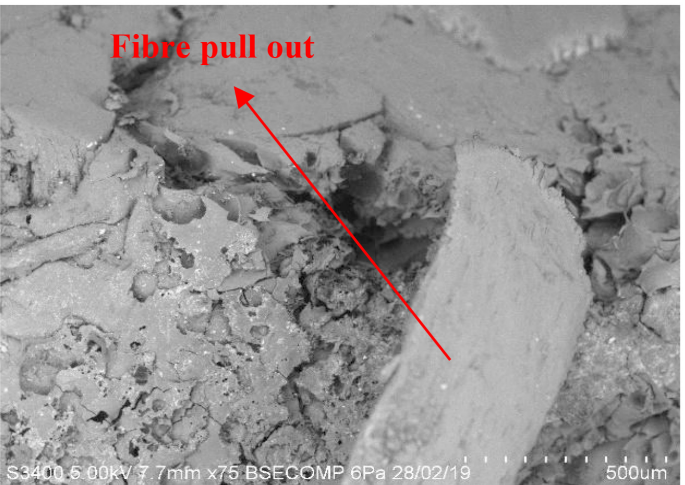

$75 \mathrm{X}$ magnification

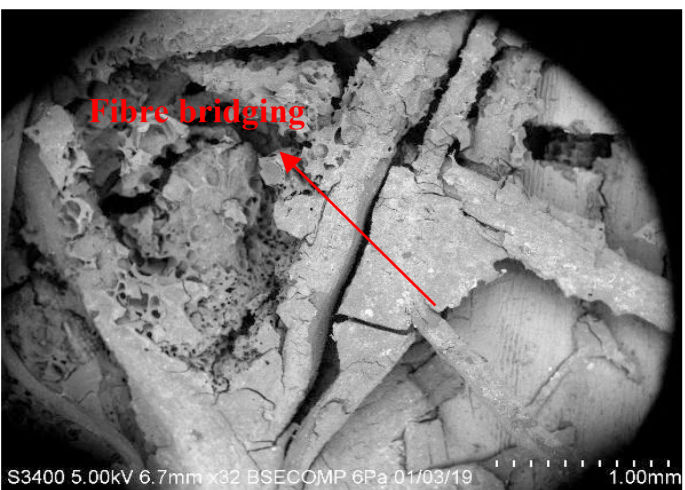

$32 \mathrm{X}$ magnification 


\section{Continued}

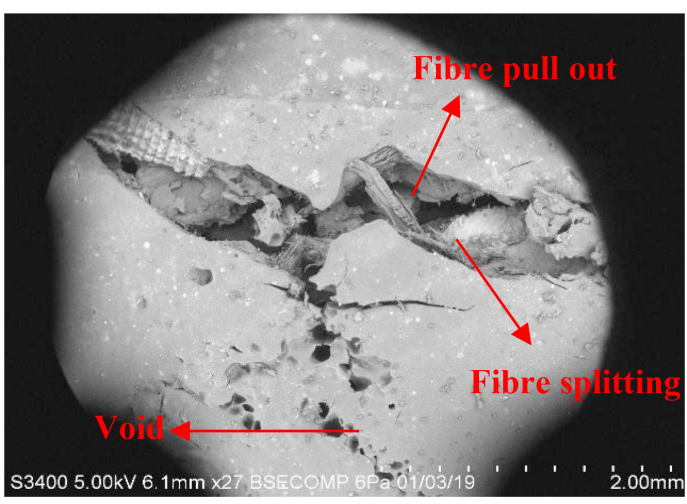

27X magnification

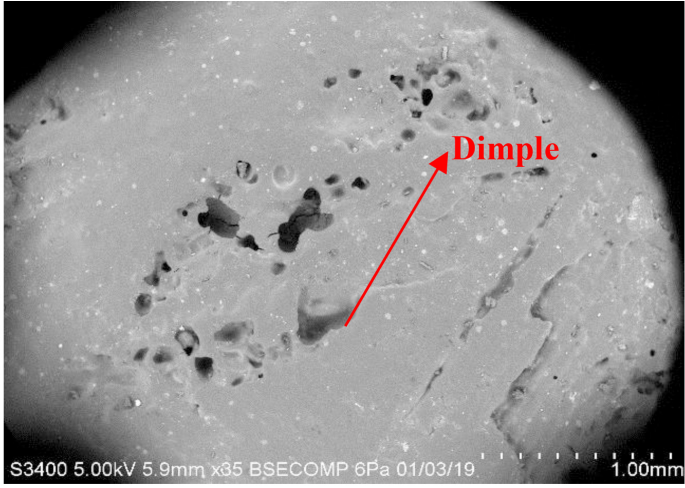

35X magnification

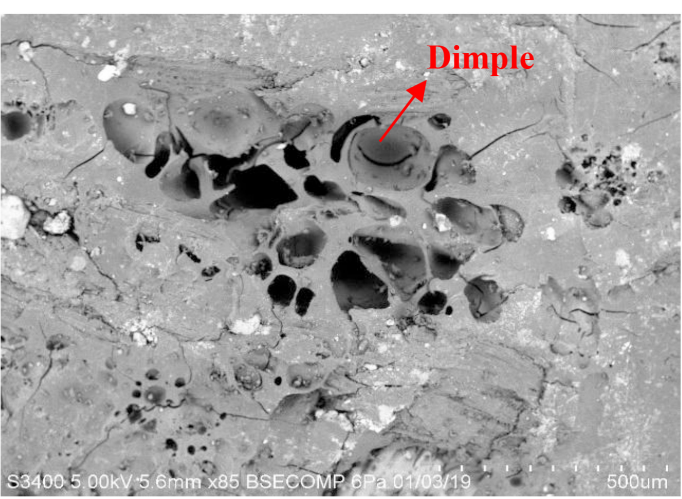

85X magnification

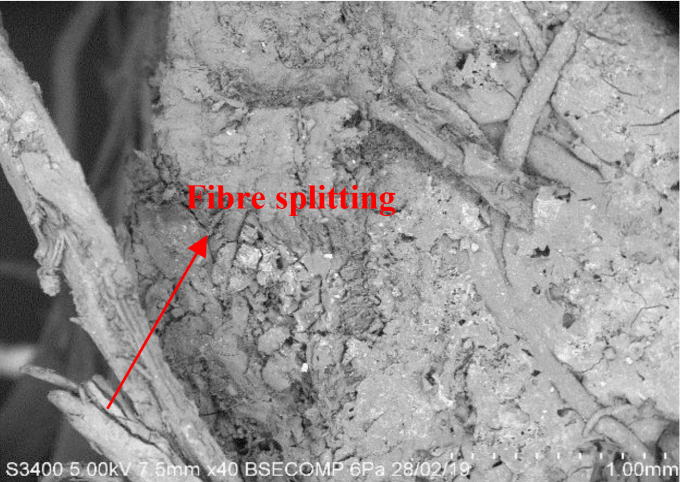

40X magnification

The micrographs obtained from the SEM imaging showed dimple, void, fibre pull out and matrix cracking as the main reasons of the breakage of the specimens. Hence, to study the microstructure of the sample under Scanning Electron Microscope, fractography analysis is required to identify the exact failure outcomes. Despite of the utilization of SEM in observing the samples, there are several challenges that needed to be taken into consideration while conducting SEM test. An experience personnel is needed to prepare the samples and conduct SEM test as there is a risk of radiation exposure resulted by the scattered electron from the sample surface if it is not properly handled. Other than that, only a small portion of sample can be fitted into the vacuum chamber which can handle the vacuum pressure. Hence, the surface area observed under the SEM will be limited.

\section{Conclusion}

In summary, there are various advantages of natural fibre in the construction industry. Their mechanical properties have contributed to the implementation of the honeycomb sandwich panel in construction industries. However, there are not many researches that have been done on natural fibre honeycomb sandwich structure in order to improve the performances. Thus, this paper will help to review the testing methods and the standard that can be referred to study the me- 
chanical behaviours of natural fibre honeycomb sandwich structure. The microstructure defects that have been found in previous research under Scanning Electron Microscope examination also will help to tackle the failure mechanisms of the structure. Further research of natural fibre honeycomb sandwich structure is highly required as it will be very beneficial in the academic world to find ways of improvisation as an attempt to tackle the problems faced for future development of natural fibre honeycomb sandwich structure.

\section{Acknowledgements}

The author would like to thank the whole research team who were involved in this research. On behalf of the Advance Composite Group, the author would like to thank Universiti Malaysia Sabah for providing the opportunity, funding and platform for this research to take place.

\section{Conflicts of Interest}

The authors declare no conflicts of interest regarding the publication of this paper.

\section{References}

[1] Schaedler, T.A. and Carter, W.B. (2016) Architected Cellular Materials. Annual Review of Material Research, 46, 187-210. https://doi.org/10.1146/annurev-matsci-070115-031624

[2] Sun, G., Zhang, J., Li, S., Fang, J., Wang, E. and Li, Q. (2019) Dynamic Response of Sandwich Panel with Hierarchical Honeycomb Cores Subject to Blast Loading. Thin-Walled Structure, 142, 499-515. https://doi.org/10.1016/j.tws.2019.04.029

[3] Liu, J., Chen, W., Hao, H. and Wang, Z. (2019) Numerical Study of Low-Speed Impact Response of Sandwich Panel with Tube Filled Honeycomb Core. Composite Structure, 220, 736-748. https://doi.org/10.1016/j.compstruct.2019.04.023

[4] Wu, X, Yu, H., Guo, L., Zhang, L., Sun, X. and Chai, Z. (2019) Experimental and Numerical Investigation of Static and Fatigue Behaviours of Composites Honeycomb Sandwich Structure. Composite Structure, 213, 165-172. https://doi.org/10.1016/j.compstruct.2019.01.081

[5] Chen, Z., Yan, N., Deng, J. and Smith, G. (2011) Flexural Creep Behaviours of Sandwich Panels Containing Kraft Paper Honeycomb Core and Wood Composite Skins. Material Science Engineering: A, 528, 5621-5626. https://doi.org/10.1016/j.msea.2011.03.092

[6] Wang, J., Shi, C., Yang, N., Sun, H., Liu, Y. and Song, B. (2018) Strength, Stiffness, And Panel Peeling Strength of Carbon Fiber-Reinforced Composite Sandwich Structures with Aluminium Honeycomb Cores for Vehicle Body. Composite Structure, 184, 1189-1196. https://doi.org/10.1016/j.compstruct.2017.10.038

[7] Bitzer, T. (2016) Honeycomb Technology: Materials, Design, Manufacturing, Application and Testing. Springer Netherlands, Dordrecht.

[8] Sun, G., Huo, X., Chen, D. and Li, Q. (2017) Experimental and Numerical Study on Honeycomb Sandwich Panels under Bending and In-Panel Compression. Materials \& Design, 133, 154-168. https://doi.org/10.1016/j.matdes.2017.07.057

[9] Faruk, O., Bledzki, A.K., Fink, H.P. and Sain, M. (2012) Biocomposites Reinforced 
with Natural Fibers: 2000-2010. Progress in Polymer Science, 37, 1552-1596. https://doi.org/10.1016/j.progpolymsci.2012.04.003

[10] Maheswari, C.U., Reddy, K.O, Muzenda, E., Shukla, M. and Varada, R.A. (2013) Mechanical Properties and Chemical Resistance of Short Tamarind Fiber Unsaturated/Polyester Composites: Influence of Fiber Modification and Fiber Content. International Journal of Polymer Analysis and Characterisation, 18, 520-533. https://doi.org/10.1080/1023666X.2013.816073

[11] Sandesh Kiran, S. and Rajaprakash, B.M. (2019) Standard Testing Methods for Natural Fiber based Hybrid Sandwich Composites. International Journal of Engineering Research \& Technology, 8, 574-585.

[12] Hussain, M., Khan, R. and Abbas, N. (2019) Experimental and Computational Studies on Honeycomb Sandwich Structures Under Static and Fatigue Bending Load. Journal of King Saud University-Science, 31, 222-229.

https://doi.org/10.1016/j.jksus.2018.05.012

[13] Stocchi. A., Colabella, L., Cisilino, A. and Álvarez, V. (2014) Manufacturing and Testing of a Sandwich Panel Honeycomb Core Reinforced With Natural-Fiber Fabrics. Materials and Design, 55, 394-403. https://doi.org/10.1016/j.matdes.2013.09.054

[14] Jundam, M.F., Shah, M.K.M, Kari, M. and Madato, L. (2020) Investigation of Oil Palm Empty Fruit Bunch (OPEFB) Embedded with Artocarpus Odorattisimus Mechanical Behaviour as an Alternative Replacement for Raw Material in Wood Industry. IOP Conference Series: Materials Science and Engineering, 834, Article ID: 012007. https://doi.org/10.1088/1757-899X/834/1/012007 